\title{
Grupos cuasifamiliares y amor en los internados psiquiátricos
}

\author{
Carlos Munizaga \\ Maria T. Soto
}

En trabajos anteriores a través de los años hemos mostrado cómo la exploración antropológica permite descubrir muchos tipos de grupos y estructuras informales que nacen dentro de un internado psiquiátrico, por ejemplo, entre los crónicos (Mun1zaGa et al., 1966). Alli se esbozaron, más recientemente, algunos que se asemejan a las familias de la sociedad externa (MunizaGa, 1987 a y b), los que con más detalle denominamos "cuasifamiliares" (MunizaGa y Soto, 1988, m.s.). Excluimos, pues, las relaciones sentimentales y sexuales fugaces, remitiéndonos, en este artículo, a las relaciones permanentes.

A medida que exploramos el campo, y sobre todo, ultimamente, el de los grupos familiares, nos preocupa la necesidad de profundizar las supuestas funciones sociales, morales y terapéuticas de estos grupos que presentan larga permanencia, pero están insuficientemente descritos científicamente, aunque son de amplio conocimiento del personal médico psiquiátrico.

Recientemente, al estudiar estos grupos "cuasifamiliares" en tres hospitales psiquiátricos chilenos (el de Santiago "J. Horwitz B.", el de Putaendo y el de Viña del Mar), nos ha llamado la atención la definida configuración sentimental, de cooperación, de permanencia a veces de largos años, la atracción mutua heterosexual que presentan. Llaman, además, la atención las definiciones que estos grupos tienen de si mismos, la claridad de sus futuros proyectos de vida en común, proyectos que comprenden sueños como el de la casa propia, su alhajamiento, el deseo de procrear y de legitimar la relación. Especialmente nos ha llamado la atención la relación que las penetra que la calificamos, y los mismos pacientes califican, como amor.

Más que el descubrimiento mismo de estas "familias", nacidas dentro del sistema de la institución amurallada y la riqueza teórica que implica su análisis, nos ha preocupado un aspecto práctico. Este es que ellas carecen de protección jurídica formal; que estos grupos y 
parejas de alienados que conviven y se "aman" pueden ser amputados, separados arbitrariamente, a veces por simple ignorancia de su existencia por parte de la autoridad administrativa o médica. Por eso es que declaramos que nuestra mayor aspiración sería la de que la revelación etnográfica de estas realidades fuera un estímulo para las entidades administrativas, médicas y comunitarias. Para que ellas demandaran una juridicidad protectiva eficaz ${ }^{*}$ de estas familias. El triunfo de la Etnografía estaría aqui en ayudar a descubrir y configurar los bienes jurídicos espirituales y materiales que están en el núcleo de estos grupos "familiares", para que puedan ser, por ahora, por lo menos, preservados, salvaguardados sus valores y potencialidades. Después, y esto está en camino, pueden discutirse las implicaciones teóricas agudamente, cuantificarse, comprobar asociaciones que, desde ya, se advierten, y que discutimos brevemente al final (pág. 70 de este trabajo).

En realidad, los juristas han construido normas relativas al paciente psiquiátrico, pero principalmente con vista a la internación, a la administración de sus bienes, a su capacidad civil, imputabilidad y responsabilidad penal, etc. Pero no hemos encontrado literatura jurídica, administrativa, relativa a la protección de estas creaciones sociales familiares, a la intimidad social, sentimental, sexual, amorosa que radica en estos grupos. En realidad esto no es culpa de los juristas. Es la comunidad, a base de indagaciones etnográficas y sociales, la que tiene que mostrar al mundo de la juridicidad estas realidades y valores humanos, para que el jurista construya las figuras legales que las consideren y protejan.

Sólo artículos circunstanciales, pero incisivos y pertinentes como el de la Dra. Cordero, 1987, que es literario, o la canción "Sólo pienso en ti", del cantante español Víctor Manuel, se refieren a formas de amor permanente entre alienados. En la Revista de Psiquiatría, Venegas y Cepeda, 1988, consideran formas de protección y derechos de los pacientes del Hospital de Putaendo, y hablan de proteger la intimidad de ellos, lo que podria vincularse a los grupos "familiares".

\section{FreCUENC1A DE GRupos FAMILIARES EN EL Hospital Psiquiát Rico de Putaendo}

La existencia de tales grupos familiares es un fenómeno también cuantitativamente importante. Así, en el Hospital de Putaendo la Dra. Soto, uno de los coautores, ha registrado alrededor de 15 de estos grupos, lo que constituye más o menos el $5,2 \%$ de los 480 pacientes crónicos. Si a éstos se agregan otros grupos por determinar y una cantidad de pacientes involucrados con las parejas, por relaciones sexuales

\footnotetext{
* Eficaz en el sentido que tiene esta palabra en la teoría jurídica, de real y concreta, satisfactoria, protección.
} 
transitorias, presentes o pasadas, este porcentaje puede elevarse a $12 \%$. En consecuencia, las relaciones "cuasifamiliares" involucran a un número importante de pacientes del Hospital.

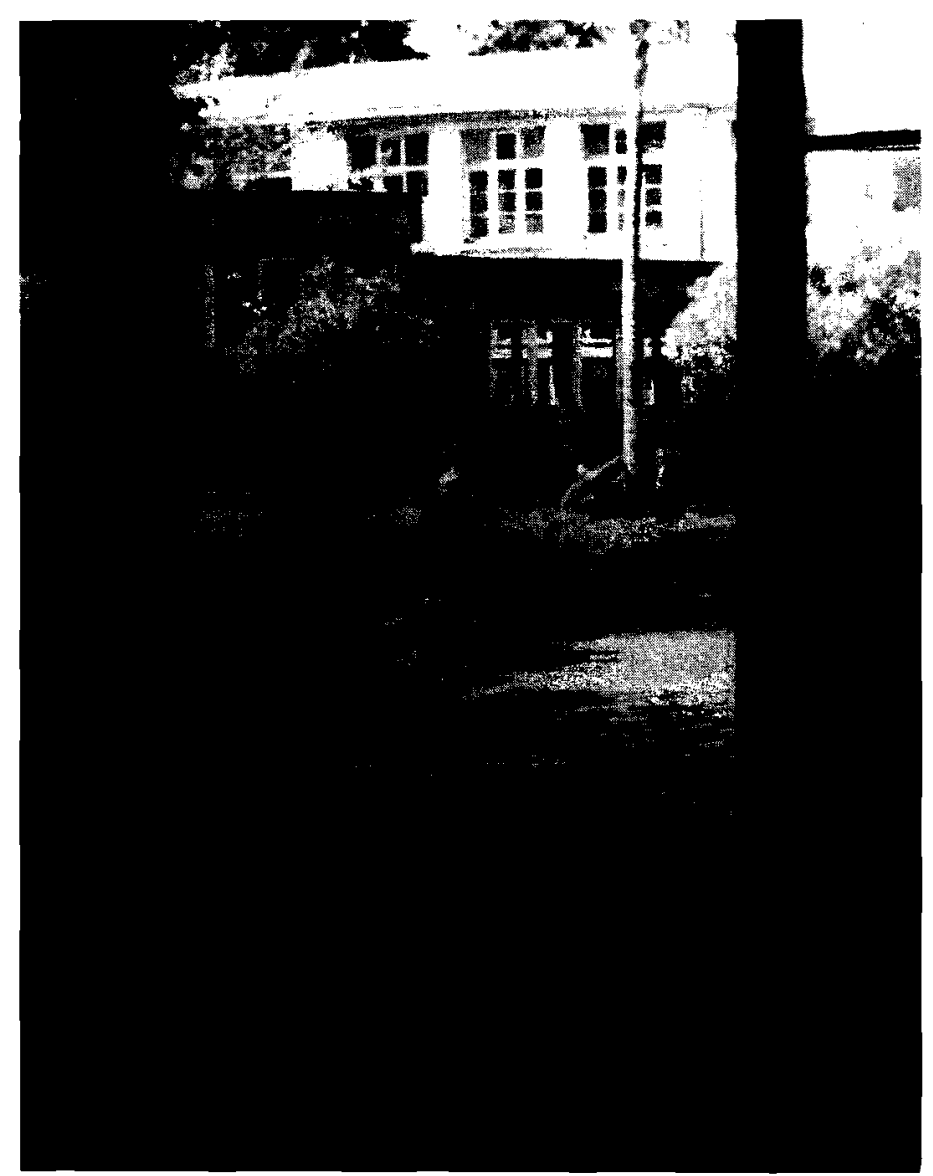

Carmen y Guillermo buscando un espacio juntos... Pareja $\mathrm{N}^{\circ} 5$ del Cuadro $N^{\circ}$ 1. Hospital Psiquiátrico de Putaendo.

\section{VARIEdad de grupos Famillares del Hospital de Putaendo}

Los grupos familiares de Putaendo presentan formas monogámicas, poligámicas y poliándricas. A base de las hasta ahora registradas elaboramos el Cuadro $\mathrm{N}^{\circ}$ l que tiene el objeto fundamental de mostrar la variedad de grupos de este tipo, en pág. 64 siguiente. 
CUADRO $\mathrm{N}^{\circ} 1$

GRUPOS “FAMILIARES” DE PACIENTES DEL HOSPITAL PSIQUIATRICO DE PUTAENDO

Y ALGUNAS CARACTERISTICAS DE ELLOS

\begin{tabular}{|c|c|c|c|c|c|c|c|c|c|}
\hline \multirow{2}{*}{$\begin{array}{c}\text { No } \\
\text { del } \\
\text { grupo }\end{array}$} & \multicolumn{2}{|c|}{$\begin{array}{l}\text { No de } \\
\text { miembros }\end{array}$} & & \multirow[t]{2}{*}{ Edad } & \multirow[t]{2}{*}{ Duración } & \multirow{2}{*}{$\begin{array}{l}\text { Tipo de } \\
\text { grupo }\end{array}$} & & \multirow[t]{2}{*}{ Diagnóstico } & \multirow[t]{2}{*}{ Observaciones } \\
\hline & $\mathbf{H}$ & $\mathbf{M}$ & & & & & & & \\
\hline \multirow{2}{*}{1} & \multirow{2}{*}{1} & \multirow{2}{*}{1} & $\mathbf{M}$ & 40 años & \multirow{2}{*}{$\begin{array}{l}\text { Perma- } \\
\text { nente }\end{array}$} & \multirow{2}{*}{$\begin{array}{l}\text { "Familia" } \\
\text { monógama }\end{array}$} & $\mathbf{M}$ & Retardo mental & \multirow[t]{2}{*}{ El tenía antes relaciones homosexuales. } \\
\hline & & & $\mathrm{H}$ & 18 años & & & $\mathrm{H}$ & $\begin{array}{l}\text { Daño cerebral } \\
\text { orgánico. }\end{array}$ & \\
\hline \multirow{2}{*}{2} & \multirow{2}{*}{1} & \multirow{2}{*}{1} & M & 88 años & \multirow{2}{*}{$\begin{array}{l}\text { Perma- } \\
\text { nente } \\
\text { ( } 2 \text { meses })\end{array}$} & \multirow{2}{*}{$\begin{array}{l}\text { "Familia" } \\
\text { monógama }\end{array}$} & $\mathbf{M}$ & Sindrome & \\
\hline & & & $\mathrm{H}$ & 29 años & & & $\mathbf{H}$ & $\begin{array}{l}\text { Esquizofrenia } \\
\text { paranoidea. }\end{array}$ & \\
\hline \multirow{3}{*}{3} & \multirow{3}{*}{2} & \multirow{3}{*}{1} & $\mathbf{M}$ & 45 años & \multirow{3}{*}{$\begin{array}{l}\text { Perma- } \\
\text { nente } \\
(5 \text { años })\end{array}$} & \multirow{3}{*}{$\begin{array}{l}\text { "Familia" } \\
\text { poliánd rica }\end{array}$} & $\mathbf{M}$ & Retardo mental & \multirow{3}{*}{$\begin{array}{l}\text { La mujer tiene relaciones "sentimenta- } \\
\text { les" con el hombre postrado y sexuales } \\
\text { con el otro. }\end{array}$} \\
\hline & & & $\mathrm{H}$ & 30 años & & & & severo. & \\
\hline & & & $\begin{array}{l}\mathrm{H} \\
2\end{array}$ & 45 años & & & $\begin{array}{l}\mathrm{H} \\
\mathbf{1} \\
\mathrm{H} \\
2\end{array}$ & $\begin{array}{l}\text { Retardo mental. } \\
\text { Distrofia muscu- } \\
\text { lar. Postrado. } \\
\text { Retardo mental. }\end{array}$ & \\
\hline \multirow[b]{2}{*}{4} & \multirow[b]{2}{*}{1} & \multirow[b]{2}{*}{1} & $M$ & 30 años & \multirow{2}{*}{$\begin{array}{l}\text { Perma- } \\
\text { nente } \\
\text { (8 años) }\end{array}$} & \multirow[t]{2}{*}{$\begin{array}{l}\text { "Familia" } \\
\text { monógama }\end{array}$} & $\mathbf{M}$ & $\begin{array}{l}\text { Retardo mental } \\
\text { moderado. }\end{array}$ & \multirow{2}{*}{$\begin{array}{l}\text { La mujer mantiene, además, relaciones } \\
\text { sexuales (prostitución) con pacientes } \\
\text { agudos o de policlínico. } \\
\text { Su "marido" le prohíbe unirse con pa- } \\
\text { cientes crónicos. }\end{array}$} \\
\hline & & & $\mathbf{H}$ & 63 años & & & $\mathrm{H}$ & $\begin{array}{l}\text { Esquizofrenia } \\
\text { defectual. }\end{array}$ & \\
\hline \multirow[b]{2}{*}{5} & \multirow[b]{2}{*}{1} & \multirow[b]{2}{*}{1} & $\mathbf{M}$ & 53 años & \multirow{2}{*}{$\begin{array}{l}\text { Perma- } \\
\text { nente } \\
\text { (12 años } \\
\text { o más). }\end{array}$} & \multirow[t]{2}{*}{$\begin{array}{l}\text { "Familia" } \\
\text { monógama }\end{array}$} & $\mathbf{M}$ & $\begin{array}{l}\text { Retardo mental } \\
\text { moderado. }\end{array}$ & \multirow{2}{*}{$\begin{array}{l}\text { No mantiene contacto sexual, mientras } \\
\text { "no se casen" (decisión parece ser de } \\
\text { ella). }\end{array}$} \\
\hline & & & $\mathbf{H}$ & 71 aก̃os & & & $\mathrm{H}$ & Esquizofrenia & \\
\hline
\end{tabular}


Cuadro $\mathrm{N}^{\circ} 1$ (Continuación)

\begin{tabular}{|c|c|c|c|c|c|c|c|c|c|}
\hline \multirow{2}{*}{$\begin{array}{c}\text { No } \\
\text { del } \\
\text { grupo }\end{array}$} & \multicolumn{2}{|c|}{$\begin{array}{l}N^{\circ} \mathrm{de} \\
\text { miembros }\end{array}$} & & \multirow[t]{2}{*}{ Edad } & \multirow[t]{2}{*}{ Duración } & \multirow{2}{*}{$\begin{array}{l}\text { Tipo de } \\
\text { grupo }\end{array}$} & & \multirow[t]{2}{*}{ Diagnóstico } & \multirow[t]{2}{*}{ Observaciones } \\
\hline & $\mathbf{H}$ & $\mathbf{M}$ & & & & & & & \\
\hline \multirow[b]{2}{*}{6} & \multirow[b]{2}{*}{1} & \multirow[b]{2}{*}{1} & M & 26 años & \multirow{2}{*}{$\begin{array}{l}\text { Perma- } \\
\text { nente } \\
\text { (4 años) }\end{array}$} & \multirow{2}{*}{$\begin{array}{l}\text { "Familia" } \\
\text { monógama }\end{array}$} & $\mathbf{M}$ & Retardo mental. & \multirow{2}{*}{$\begin{array}{l}\text { El novio falleció hace un año y dejó } \\
\text { encargada a su novia a otro paciente } \\
\text { de } 24 \text { años. Dando lugar a la relación } \\
\text { delgrupo } 7 \text {. }\end{array}$} \\
\hline & & & $\mathrm{H}$ & 28 años & & & $\mathrm{H}$ & Retardo mental. & \\
\hline \multirow{2}{*}{7} & \multirow{2}{*}{1} & \multirow{2}{*}{1} & $\mathbf{M}$ & 26 años & \multirow{2}{*}{$\begin{array}{l}\text { Perma- } \\
\text { nente } \\
\text { ( } 4 \text { meses) }\end{array}$} & \multirow{2}{*}{$\begin{array}{l}\text { "Familia" } \\
\text { monógama }\end{array}$} & $\mathbf{M}$ & Retardo mental. & \multirow{2}{*}{$\begin{array}{l}\text { El grupo duró } 4 \text { meses, después el encar- } \\
\text { gado de la "viuda" (del grupo } \mathrm{N}^{\circ} \text { 6) no } \\
\text { resistió el carácter de ella. Este varón } \\
\text { ha iniciado una ligazón afectiva con otra } \\
\text { mujer que es muy parecida físicamente a } \\
\text { la viuda que se le encargó. }\end{array}$} \\
\hline & & & $\mathbf{H}$ & 24 años & & & $\mathbf{H}$ & Retardo mental. & \\
\hline \multirow{3}{*}{8} & \multirow{3}{*}{1} & \multirow{3}{*}{2} & $\begin{array}{l}M \\
1\end{array}$ & 34 años & \multirow{3}{*}{$\begin{array}{l}\text { Perma- } \\
\text { nente } \\
\text { ( } 4 \text { años) }\end{array}$} & \multirow[t]{3}{*}{$\begin{array}{l}\text { "Familia" } \\
\text { poligámica }\end{array}$} & $\begin{array}{l}M \\
1\end{array}$ & $\begin{array}{l}\text { Deficiente mental. } \\
\text { Postrada. }\end{array}$ & \multirow{3}{*}{$\begin{array}{l}\text { La mujer de } 70 \text { años cuida a la otra mu- } \\
\text { jer y al varón; y se preocupa de adminis- } \\
\text { trar y cuidar las pertenencias del grupo. } \\
\text { El parece tener relaciones sexuales con } \\
\text { ambas. La más joven, a veces, hace escán- } \\
\text { dalos para no dejar que el varón vaya a } \\
\text { su trabajo. }\end{array}$} \\
\hline & & & $\begin{array}{l}\mathrm{M} \\
2\end{array}$ & 70 años & & & $\begin{array}{l}M \\
2 \\
\end{array}$ & $\begin{array}{l}\text { Retardo mental, } \\
\text { muda y ciega. }\end{array}$ & \\
\hline & & & $\mathrm{H}$ & 65 años & & & $\mathrm{H}$ & $\begin{array}{l}\text { Sin diagnóstico. } \\
\text { Ciego, sordo y } \\
\text { mudo. }\end{array}$ & \\
\hline \multirow{5}{*}{9} & \multirow{5}{*}{3} & \multirow{5}{*}{1} & $\mathbf{M}$ & 24 aก̃os & \multirow{5}{*}{$\begin{array}{l}\text { Perma- } \\
\text { nente } \\
\text { (4 años) }\end{array}$} & \multirow[t]{5}{*}{ ¿Poliandria? } & $\mathbf{M}$ & Retardo mental, & \multirow{5}{*}{$\begin{array}{l}\text { La mujer es la líder protectora. Siempre } \\
\text { está con los } 3 \text { varones, ayudándolos. No } \\
\text { existirían relaciones sexuales ni con ella } \\
\text { ni entre ellos. Es posible que este grupo, } \\
\text { posteriormente, sea eliminado o que su } \\
\text { interpretación sea cambiada, por ejem- } \\
\text { plo, por una especie de familia incomple- } \\
\text { ta en la que hay una madre y tres hijos; } \\
\text { o bien, } 4 \text { hermanos huérfanos. }\end{array}$} \\
\hline & & & $\begin{array}{l}\mathrm{H} \\
1\end{array}$ & 24 años & & & & $\begin{array}{l}\text { te que el de los } \\
\text { varones. }\end{array}$ & \\
\hline & & & $\begin{array}{l}\mathrm{H} \\
2\end{array}$ & 26 años & & & $\begin{array}{l}\mathrm{H} \\
\mathrm{I}\end{array}$ & $\begin{array}{l}\text { Retardo mental } \\
\text { profundo. }\end{array}$ & \\
\hline & & & $\begin{array}{l}\mathrm{H} \\
3\end{array}$ & 28 años & & & $\begin{array}{l}H \\
2\end{array}$ & $\begin{array}{l}\text { Retardo mental } \\
\text { profundo. }\end{array}$ & \\
\hline & & & & & & & $\begin{array}{l}\mathrm{H} \\
3\end{array}$ & $\begin{array}{l}\text { Retardo mental } \\
\text { profundo. }\end{array}$ & \\
\hline
\end{tabular}

$\mathbf{M}=$ Mujer.

$\mathrm{H}=$ Hombre. 


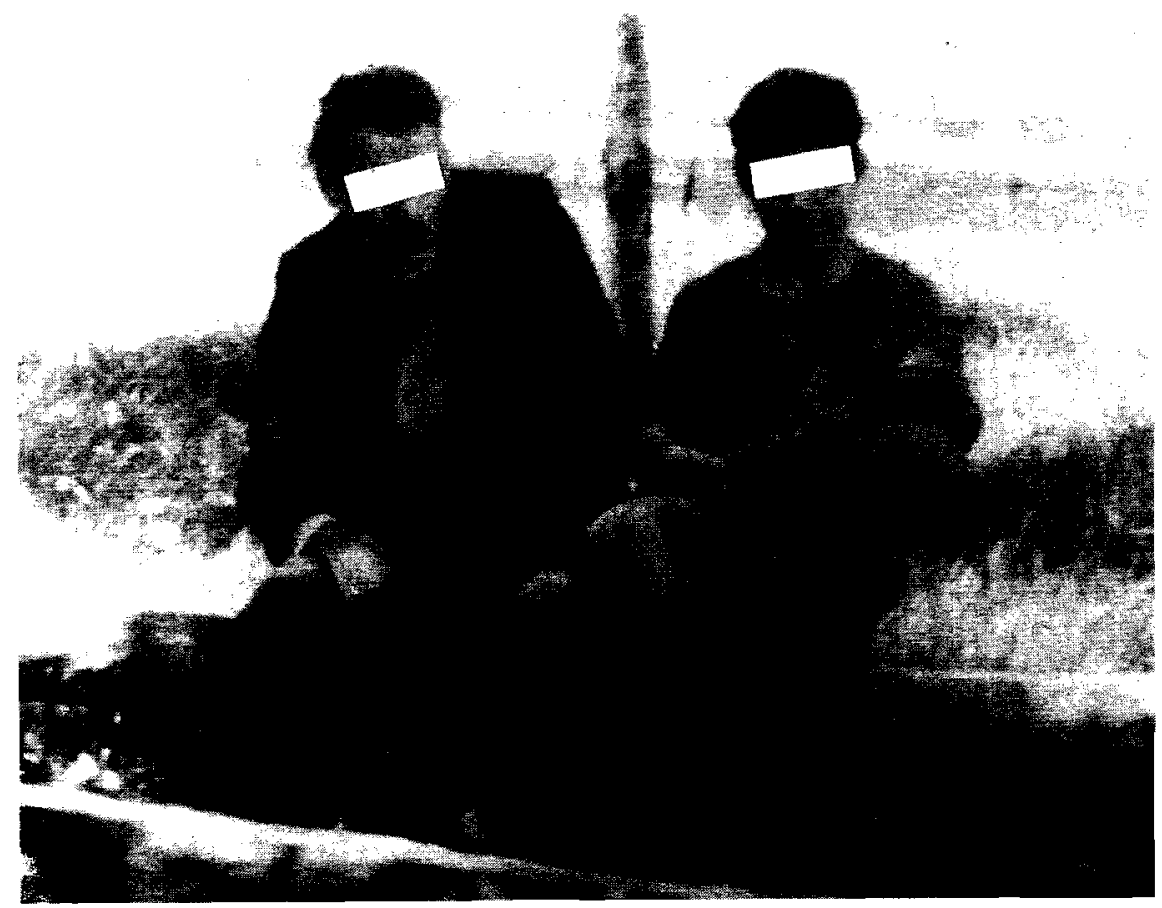

Nora y Miguel, pareja reciente. Hospital Psiquiátrico de Putaendo. (No está en las descripciones de este trabajo.)

(Fotos tomada por el psicólogo Sr. Ricardo Canales.)

\section{Parejas familiares del Hospital Psiquiátrico de Santiago (J. Horwitz B.)}

En este hospital estamos realizando el mismo estudio. Pero recurriendo a una metodología más bien cualitativa (observación, entrevistas intensivas), para indagar y describir la forma concreta de las relaciones sociales, el comportamiento sexual, las definiciones que las parejas permanentes tienen de sí mismas.

De este estudio que, por el momento, comprende dos parejas monogámicas, hemos extraído algunas características comunes de ellas, para iniciar la elaboración de una pauta de investigación, observación y análisis, la que presentamos en el Cuadro $\mathrm{N}^{\circ} 2$ pág. 67. Las indagaciones cuantitativas de este hospital son materia de un estudio que estamos realizando con la colaboración de la terapeuta ocupacional Alejandra Amirá. 


\section{Cuadro $\mathrm{N}^{\circ} 2$}

\section{LAS DOS PAREJ AS DEL HOSPITAL PSIQUIATRICO DE SANTIAGO. ALGUNAS CARACTERISTICAS COMUNES}

\begin{tabular}{|c|c|}
\hline 1. Parejas monógamas & Ambas. \\
\hline 2. Permanencia & $\begin{array}{l}10 \text { años la primera pareja y } 4 \text { años la se- } \\
\text { gunda. }\end{array}$ \\
\hline 3. Historia anterior & $\begin{array}{l}\text { La primera pareja: varias relaciones espo- } \\
\text { rádicas heterosexuales de la mujer y del } \\
\text { varón. En la actualidad fidelidad mutua, } \\
\text { aunque se recuerda y comentan con apa- } \\
\text { rente tranquilidad estas relaciones ante- } \\
\text { riores. }\end{array}$ \\
\hline $\begin{array}{l}\text { 4. Relación pública, reconoci- } \\
\text { da, no clandestina. }\end{array}$ & Ambas parejas. \\
\hline $\begin{array}{l}\text { 5. Convivencia en tiempo libre, } \\
\text { fuera del hospital. }\end{array}$ & $\begin{array}{l}\text { Ambas salen, recorren los barrios, hacen } \\
\text { pequeñas compras y visitas a las fuentes } \\
\text { de soda. }\end{array}$ \\
\hline $\begin{array}{l}\text { 6. Reconocen, con naturalidad } \\
\text { sin ostentación, sus relacio- } \\
\text { nes sexuales. }\end{array}$ & Ambas. \\
\hline $\begin{array}{l}\text { 7. Programación de la relación } \\
\text { sexual. }\end{array}$ & $\begin{array}{l}\text { Primera pareja: sin información. } \\
\text { Segunda pareja: una vez a la semana. El } \\
\text { hombre siente deseos al quinto dia. "Más, } \\
\text { es exceso". }\end{array}$ \\
\hline $\begin{array}{l}\text { 8. Caricias, no en el acto } \\
\text { sexual. }\end{array}$ & $\begin{array}{l}\text { Primera pareja: se dan besos, bajo las pal- } \\
\text { meras del Parque Grez. }\end{array}$ \\
\hline $\begin{array}{l}\text { 9. Preocupación mutua en } \\
\text { necesidades domésticas. }\end{array}$ & Ambas. \\
\hline $\begin{array}{l}\text { 10. Definición propia de su } \\
\text { relación. }\end{array}$ & $\begin{array}{l}\text { Primera pareja: "amistad, amor". } \\
\text { Segunda pareja: atracción. Angustia de se- } \\
\text { pararse, sensación de interpenetración } \\
\text { psiquica. }\end{array}$ \\
\hline
\end{tabular}


Cuadro No 2 (continuación)

\begin{tabular}{|l|l|}
\hline $\begin{array}{l}\text { 11. Proyecto de poseer una } \\
\text { casa y enumeración de } \\
\text { objetos de alhajamiento. }\end{array}$ & $\begin{array}{l}\text { Primera pareja: con detalles. } \\
\text { Segunda pareja: también, pero no se pro- } \\
\text { fundizó en detalles (test). }\end{array}$ \\
\hline $\begin{array}{l}\text { 12. } \begin{array}{l}\text { Deseo de legitimar la } \\
\text { relación (traje de novia, } \\
\text { matrimonio). }\end{array} \\
\text { 13. Actividad on írica, vincu- } \\
\text { lada a su relación. }\end{array}$ & Ambas. \\
\hline 14. Se toman fotos. & Ambas. \\
\hline 15. Tener hijos. Esterilización. & $\begin{array}{l}\text { Primera pareja: falta información. } \\
\text { Segunda pareja: si, y aceptarían adop- } \\
\text { ción, por estar esterilizada la mujer. }\end{array}$ \\
\hline
\end{tabular}

La idea de AMOR EN LAS PaReJas del Hospit al J. HORWITZ B.

La consideración de estas parejas nos confronta con la idea que poseen del amor. En el Cuadro $\mathrm{N}^{\circ} 2$ hemos presentado algunas características de estos grupos que corresponden a lo que algunos autores, especialmente psiquiatras, consideran como indicadores importantes de la relación amorosa. La definición de la idea de amor es un tema controvertido (Fromm, PeÑa y Lllo, Roa), a lo que se agrega el hecho de que estamos ante pacientes mentales. Al respecto y para iniciar una exploración de la idea de amor en estos grupos, hemos elaborado el Cuadro $\mathrm{N}^{\circ} 3$, donde consignamos indicadores de amor (según algunos autores) en la columna de la izquierda y agregamos, en la de la extrema derecha, algunas referencias bibliográficas.

\section{El caso de la pareja poligámica del Hospital \\ Psiquiátrico de Viña del Mar}

Nos fue comunicado por el médico psiquiatra Dr. Simeón Rizo, con quien nos proponemos hacer un estudio en profundidad, así como de otras situaciones del Hospital.

Se trata de un varón que mantiene relaciones heterosexuales con dos mujeres. Una de ellas ha llegado, después de muchas experiencias sexuales esporádicas con terceros, a serle una mujer fiel. La otra mujer, aunque ligada fuertemente al mismo varón, mantiene relaciones 
sexuales con otros pacientes, a sabiendas del varón. Pero, en general, los tres conviven, pasean juntos y, como dice el Dr. Rizo, permanecen muchas veces en una actitud de adoración al varón. Este último, a su vez, parece sostener relaciones heterosexuales esporádicas con otras.

Este caso de poligamia, pues, presenta muchas de las irregularidades de las familias normales: una amante fiel y celosa; otra infiel y que ejerce una especie de prostitución. Han llegado los tres, sin embargo, a establecer un grupo fuertemente unido, y presentan una larga historia de relaciones que han cristalizado en esta forma social.

\section{Cuadro $\mathbf{N}^{\circ} 3$}

\section{ALGUNAS CARACTERISTICAS DE LAS PAREJAS. CONTRIBUCION A LA ELABORACION DE UNA PAUTA DE INVESTIGACION Y ANALISIS DE LAS “FAMILIAS". Referencias teóricas}

\begin{tabular}{|c|c|}
\hline Caracteristicas & $\begin{array}{l}\text { Idea correspondiente en algunos au- } \\
\text { tores, con respecto a parejas norma- } \\
\text { les }\end{array}$ \\
\hline $\begin{array}{l}\text { 1. Larga vida juntos, en monoga- } \\
\text { mia, fidelidad. }\end{array}$ & Peña y Lillo, 1986: 28. \\
\hline $\begin{array}{l}\text { 2. Historias anteriores de prostitu- } \\
\text { ción, homosexualidad o relacio- } \\
\text { nes no permanentes de los } \\
\text { miembros de la pareja. }\end{array}$ & $\begin{array}{l}\text { Posibles distinciones entre sexo, se- } \\
\text { xualidad, impulso sexual, Eros y } \\
\text { Amor. } \\
\text { Peña y Lillo, 1986: } 24 \text { y siguientes. } \\
\text { Lewis C.S., 1988: 109-136. }\end{array}$ \\
\hline $\begin{array}{l}\text { 3. Proyectos para el futuro y unión } \\
\text { estable de la pareja. }\end{array}$ & $\begin{array}{l}\text { Peña y Lillo, 1986: } 31 \text { y Dörr, citado } \\
\text { en la misma página. }\end{array}$ \\
\hline $\begin{array}{l}\text { 4. Proyectos que se precisan en } \\
\text { imaginar una vivienda y su alha- } \\
\text { jamiento para la vida futura de la } \\
\text { pareja, enumerando elementos } \\
\text { vitales en el pueblo chileno. }\end{array}$ & $\begin{array}{l}\text { Peña y Lillo, 1986: } 30 \text {. Dörr, } 1984 \text { y } \\
\text { Roa, 1982: 202-205. Se refieren a } \\
\text { "espacialidad", el espacio exterior } \\
\text { como reproducción del espacio inter- } \\
\text { rior, etc. }\end{array}$ \\
\hline $\begin{array}{l}\text { 5. Preocupación mutua de los } \\
\text { miembros de la pareja por la } \\
\text { salud, el vestuario, la comida } \\
\text { de ellos. }\end{array}$ & $\begin{array}{l}\text { Incluida en las caracter isticas } 1,3,4 \text {, } \\
10,12 \text {. Considerada en nuestro Có- } \\
\text { digo Civil en el matrimonio. }\end{array}$ \\
\hline 6. Agrado de estar juntos. & $\begin{array}{l}\text { Incluida en características } 1,3,4,10 \text {, } \\
11 \text {. }\end{array}$ \\
\hline
\end{tabular}


Cuadro No 3 (continuación)

\begin{tabular}{|c|c|}
\hline Características & $\begin{array}{l}\text { Idea correspondiente en algunos au- } \\
\text { tores, con respecto a parejas norma- } \\
\text { les }\end{array}$ \\
\hline $\begin{array}{l}\text { 7. Poca sofisticación, como por } \\
\text { ej., escribirse cartas de amor. }\end{array}$ & $\begin{array}{l}\text { La relación amorosa está condiciona- } \\
\text { da por la clase social, su educación y } \\
\text { costumbres que habría que estudiar. }\end{array}$ \\
\hline $\begin{array}{l}\text { 8. Experiencias on íricas de la pa- } \\
\text { reja, en que aparecen motivos } \\
\text { de su relación y conflictos. }\end{array}$ & $\begin{array}{l}\text { Conveniente revisar bibliografía so- } \\
\text { bre Sueños. }\end{array}$ \\
\hline $\begin{array}{l}\text { 9. Da la impresión que lo sexual no } \\
\text { fuera obsesivo, sino algo natural, } \\
\text { ponderado de lo que no se hace } \\
\text { ostentación (no hay bravucone- } \\
\text { ría como lo observé en otro pa- } \\
\text { ciente que se jactaba de aventu- } \\
\text { ras fugaces). }\end{array}$ & $\begin{array}{l}\text { Diferencia entre sexualidad y rela- } \\
\text { ción amorosa. (Ver característica } \\
\mathrm{N}^{\circ} 2 \text { de este cuadro.) }\end{array}$ \\
\hline $\begin{array}{l}\text { 10. Deseo de legitimizar la relación, } \\
\text { hacerla pública, en oposición a } \\
\text { la clandestinidad de la misma. }\end{array}$ & Peña y Lillo, 1986: 32. \\
\hline $\begin{array}{l}\text { 11. Preocupación por procrear y } \\
\text { conciencia de la esterilización } \\
\text { como impedimento. }\end{array}$ & $\begin{array}{l}\text { Procreación, considerada en nuestra } \\
\text { legislación civil, como elemento del } \\
\text { matrimonio (Código Civil, art. 202). }\end{array}$ \\
\hline $\begin{array}{l}\text { 12. Angustia ante separación deter- } \\
\text { minada por la autoridad. }\end{array}$ & Incluidas en referencias de $1,3,4$ \\
\hline 13. Prostitución de la "mujer". & $\begin{array}{l}\text { López Ibor (Prostitución de las ca- } \\
\text { sadas), pág. } 151 .\end{array}$ \\
\hline $\begin{array}{l}\text { 14. Rechazo de la familia externa } \\
\text { por pobreza del miembro varón. }\end{array}$ & $\begin{array}{l}\text { Problemas de estratificación eco- } \\
\text { nómica. }\end{array}$ \\
\hline
\end{tabular}

\section{IMPLICACIONES TEÓRICAS Y CONCLUSIONES}

Consignamos algunas implicancias teóricas del tema:

a) La existencia $\tan$ frecuente de estos grupos familiares presenta un problema teórico interesante. En efecto en las instituciones amuralladas, según lo expresó Gofmann en su obra clásica 
"Internados", los reclusos son "extraídos" y separados de sus familias, para ingresar a la organización o sistema que pretende remodelarlos. Aquí, en cambio, tenemos estructuras familiares intrahospital que nacen dentro del propio sistema, donde adquieren permanencia, por lo que las funciones de estas familias internas deben ser exploradas, ya que, entre otros resultados, pueden antagonizar (positiva o negativamente) con el sistema absorbente de la institución amurallada. En parte, esto implica revisar la teoría de Gofmann.

b) Es posible que percibamos desde fuera estas "familias" de pacientes como estructuras superiores en calidad humana-social, atribuyéndoseles una autonomía exagerada. Y que con esta percepción descuidemos la parte importante que tiene en el surgimiento de ellas, el sistema mismo de la institución, sus conflictos y tensiones. Desde luego la influencia del condicionamiento espacial (amurallado) puede ser, en parte, determinante de las uniones. Por otra parte, Caudill, un clásico de la antropología de hospitales psiquiátricos, señaló que había ciertas relaciones: el "mar de fondo" de los conflictos entre administrativos y médicos influía en las conductas de los pacientes, incluso en la formación de grupos de éstos. A mayores tensiones y mar de fondo en la estructura del Hospital, más formación de grupos de pacientes.

c) Sin embargo, pese a estas consideraciones, surge la interrogante teórica de: ¿por qué sólo algunas de estas historias de vida sentimental y sexual transitorias y fugaces terminan en grupos o familias permanentes?

d) Podría aceptarse que estos grupos que comparten sentimientos, sexo, bienes materiales, cooperación y proyectos de vida, serían propicios como unidades para la terapia, o, por lo menos, para la elevación del nivel humano de valores de los internos. Queda, siempre pendiente, el estudio intensivo de las relaciones entre la historia de la pareja, hasta su constitución final, por una parte, y la historia de su vida psicótica, y las vinculaciones con la rehabilitación psiquiátrica, etc., por otra.

e) Hoy, en psiquiatría, se acepta en general que el paciente debe ser tratado como miembro del sistema familiar. ¿Hemos considerado el sistema de estas familias construidas por ellos, durante su locura? Hay, entonces, a veces una doble estructura familiar que debe ingresar como dato a la ficha médica.

Terminamos, pues, este artículo con algunas argumentaciones teóricas que nos atraen, las que formalmente deberían ir al inicio. Esto es causa del inminente deseo práctico de develar con rapidez, etnográficamente, y proteger, de una vez, estos grupos que surgen en la descripción. Y lanzamos para esto sugerencias de apoyo hacia el territorio jurídico-administrativo.

Algunos expertos, con razón, tal vez, han expresado al primer autor que este artículo es un resumen demasiado escueto para que refleje el sentido teórico, metodológico y práctico de la situación. 
Cargamos con la responsabilidad de presentarlo, con el ánimo de recibir pronto observaciones y ayuda, en este terreno poco explorado, mientras seguimos la investigación principal en los hospitales citados.

\section{Agradecimientos}

Nuestros agradecimientos al Director del Hospital Psiquiátrico de Santiago, don Luis Gomberoff J., quien nos ha dado autorización para realizar esta línea de estudio dentro del hospital. Al Dr. Raúl Riquelme, Director del Departamento $\mathrm{N}^{\circ} 11$, de la misma institución, quien nos abrió la puerta de éste. A la terapeuta ocupacional señorita Alejandra Amirá Paredes, también del Departamento $N^{\circ} 11$ del hospital, quien ha trabajado directamente en las entrevistas, sugiriendo ideas. Al Dr. Simeón Rizo, del Hospital Psiquiátrico de Viña del Mar, quien está siempre interesado en estos trabajos y discutiendo creativamente $\mathrm{y}$, además, suministrando observaciones personales. A la Dra. Norma Aburto y a la enfermera de crónicos Eliana Otey, del Hospital Psiquiátrico de Putaendo, quien, con la Dra. María Teresa Soto y el psicólogo Ricardo Canales (quien obtuvo el material gráfico), colaboran en el problema dentro de dicho hospital. Al Dr. Eduardo Medina Cárdenas, profesor de la Universidad de Chile, con quien estamos siempre discutiendo trabajos. A la señora Iturrieta, a cargo de la Biblioteca del Hospital Psiquiátrico de Santiago, por su colaboración en revisar bibliografías que pudieran referirse al tema. A la Universidad de Chile, cuyo régimen de dedicación exclusiva me amplía los medios para realizar estas líneas de investigación.

\section{Bibliografía}

Caudill, W. El Hospital Psiquiátrico como camunidad terapéutica. Editorial Escuela de Buenos Aires, 1966.

Cordero V., María L. Los locos que inventaron el amor. Revista Vida Médica, Vol. $40 \mathrm{~N}^{\circ}$ 3. Publicación Oficial del Colegio Médico de Chile, A.G., p. 155. Santiago, 1988.

Frömm, Erich. Psicoanálisis de la sociedad contemporánea. F. C.E. XVI, impresión, 1987 (primera en inglés, 1955).

Goffmann, Erving. Internados. Ensayo sobre la situación de los enfermos mentales. Buenos Aires. Amorrortu Editores, 1970.

Lewis, C.S. Los cuatro amores. Afecto. Amistad. Eros. Caridad. Santiago, Editorial Universitaria.

López Ibor, Juan. Guia de la sexualidad. Barcelona, Ediciones del Grupo Latino (sin fecha).

Munizaga A., Carlos; Mujica, Gustavo; González, Manuel; Honorato, Ricardo. El sistema sociocultural en un Departamento de Enfermas Mentales Crónicas. Revista de Antropología. Años IV y V. Vol. 4, No Unico. Centro de Estudios Antropológicos. Facultad de Filosofía, Humanidades y Educación. Universidad de Chile. Santiago, 1966-67. 
Munizaga A., Carlos. Patologia de las organizaciones psiquiatricas. ¿Cuanto sabemos de la cara informal de ellas? Revista de Psiquiatría, Hospital J. Horwitz B. (IV pp. 117-124). Santiago, 1987a.

Munizaga A., Carlos. Aportes etnográficos al estudio de las organizaciones psiquiátricas. Revista de Antropología ${ }^{\circ}$ 6, pp. 27-34. Santiago, 1987b.

Munizaga A., Carlos y Dra. Soto, Maria Teresa. El amor en los internados psiquiátricos. IX Simposium de Psiquiatría de Crónicos. Hospital de Putaendo, 1988.

Peña y Lillo, Sergio. Amor y sexualidad. Editorial Universitaria. Santiago, 1986.

Roa, Armando. El mundo adolescente. Editorial Universitaria. Santiago, 1986.

Venegas C., Federico; Zepeda R., María E. Principios, orientaciones y garantías para la protección de los pacientes internados en el Hospital Psiquiatrico de Putaendo. Revista de Psiquiatría, Hospital Psiquiátrico J. Horwitz B. ISSN 0716-96X. Año V, No 2, junio, pp. 153-156. Santiago, 1988.

Víctor Manuel (cantante español). Sólo pienso en ti. Canción de la cual él es autor de la letra y música. Cassette Stereo. Sello Grabador CBS. Record Chile Limitada (P), 1984. 